\title{
Effect of Sand Relative Density inside the Geotextile Pillow on the Bearing Capacity of Pad Foundation
}

\author{
Wimala Mia $^{1, a}$ and Wibowo Herianto ${ }^{2, b}$ \\ ${ }^{1}$ Institut Teknologi Nasional. JI.PKH. Hasan Mustapa No.23, Bandung 40124, Indonesia \\ ${ }^{2}$ Universitas Kristen Maranatha. Jl. Prof. Drg. Suria Sumantri 65, Bandung 40164, Indonesia \\ amiasoejoso@gmail.com, herianto2008@gmail.com
}

Keywords: Geotextiles Pillow, Bearing Capacity, Pad Foundation, Relative Density

\begin{abstract}
A foundation is used to support a building or structure and transmits loads directly to the underlying soil or rock. It must provide an adequate factor of safety against failure of the supporting strata, as well as failure of any excessive settlement which can interfere the function of the structure. Ultimate bearing capacity of a specific foundation is one parameter commonly used to describe the performance criteria of both the soil and the structure above. It can be improved by the inclusion of reinforcements in the ground such as geotextiles. In practice, geotextiles are normally placed directly on the soil in the form of sheet and then covered with aggregates. This research was conducted specifically to investigate the effect of different sand relative densities inside the geotextile pillow, an alternative of geotextile installations in practices, on the bearing capacity of pad foundation by laboratory experiments. A-10 $\mathrm{cm}$ x $10 \mathrm{~cm}$ pad foundation model was developed in a $1 \mathrm{~m} 3$ box filled with sand to actualize this experiment. Geotextile sheet was formed into a pillow, filled with sand with different relative densities and placed at a predetermined depth from the sand surface. As a result, the bearing capacity of the pad foundation model was proved to increase by $50 \%$ using a sheet of geotextile compared to the one without any geotextile. Moreover, to the same condition, the use of a geotextile pillow with different sand relative densities inside the pillow, i.e. $30 \%, 50 \%$ and $70 \%$ remarkably improved the bearing capacity of the pad foundation model from $150 \%$ to $525 \%$. Among the experiment results using a geotextile pillow, the $66.67 \%$ addition of sand relative density increased the bearing capacity of a pad foundation model by $100 \%$ and $150 \%$ with $133.33 \%$ of sand relative density. It showed that the increase of the sand relative density inside the geotextile pillow was directly proportional to the increase of the bearing capacity of the pad foundation model.
\end{abstract}

\section{Introduction}

A foundation is used to support a building or structure and transmits loads directly to the underlying soil or rock. The overall performance and functional viability of a foundation depends largely on the interaction between the structural unit above and the soil/rock unit below. A foundation must provide an adequate factor of safety against failure of the supporting strata, as well as failure of any excessive settlement which can disturb the function of the structure. The bearing capacity of soil can be defined as the resistance of the foundation when maximum pressure is applied from the foundation to the soil without arising shear failure in the soil. The load per unit area of the foundation at which the shear is expected to fail, i.e. a collapse will take place, is called the ultimate bearing capacity.

The ultimate bearing capacity of the foundation can be improved by the inclusion of reinforcements in the ground especially for construction on weak and saturated soils. For the last decades, several studies have been conducted based on the laboratory model and field test, related to the beneficial effects of the geotextiles, on the load bearing capacity of soils in the shallow foundations, road pavement and slope stabilizations. Geotextiles are able to receive the load transferred to the soil to a depth of some without collapse, having the ability to separate, filter, 
reinforce, protect and drain. In practice, geotextiles are commonly placed directly on the soil in the form of sheet and then covered with aggregates.

In view of the above, the research aimed to investigate the effect of different sand relative densities inside the geotextile pillow on the bearing capacity of the pad foundation. The geotextile pillow was proposed in this research to be an alternative of geotextile installations in real practices. In addition, this research was focused on square pad foundation due to the tendency of its wide application on residential buildings in Indonesia.

\section{Experimental Study}

Material Used: Sand and Geotextile In this experiment, dry sand was used as the main material for foundation as well as the one put inside the geotextile pillow. Several physical and mechanical properties were tested for sand as shown in Table 1. According to Unified Soil Classification System (USCS), the soil was classified as well-graded sand. Another main material used in this experiment was the geotextile itself. Bima Geoteks ${ }^{\circledR}$ Woven Geotextile BW250 was used both in the form of pillow, as well as in the form of sheet as comparison. The specification of this type of geotextile is presented in Table 2 .

Table 1 Properties of Sand

\begin{tabular}{ll}
\hline \multicolumn{1}{c}{ Characteristic } & \multicolumn{1}{c}{ Value } \\
\hline Specific gravity $(\mathrm{Gs})$ & 2.62 \\
$\mathrm{D}_{60}$ & $1.1 \mathrm{~mm}$ \\
$\mathrm{D}_{10}$ & $0.24 \mathrm{~mm}$ \\
Uniformity coefficient $(\mathrm{Cu})$ & 4.583 \\
Maximum unit weight $\left(\gamma_{\max }\right)$ & $1.599 \mathrm{gr} / \mathrm{cm}^{3}$ \\
Minimum unit weight $\left(\gamma_{\min }\right)$ & $1.342 \mathrm{gr} / \mathrm{cm}^{3}$ \\
Dry unit weight $\left(\gamma_{\text {dry }}\right)$ & For relative density $(\mathrm{Dr})$ of $30 \%, \gamma_{\text {dry }}=1.410 \mathrm{gr} / \mathrm{cm}^{3}$ \\
& For relative density $(\mathrm{Dr})$ of $50 \%, \gamma_{\text {dry }}=1.459 \mathrm{gr} / \mathrm{cm}^{3}$ \\
& For relative density $(\mathrm{Dr})$ of $70 \%, \gamma_{\text {dry }}=1.512 \mathrm{gr} / \mathrm{cm}^{3}$ \\
Shear angle $(\phi)$ & For relative density $(\mathrm{Dr})$ of $30 \%, \phi=31^{\circ}$ \\
& For relative density $(\mathrm{Dr})$ of $50 \%, \phi=38^{\circ}$ \\
& For relative density $(\mathrm{Dr})$ of $70 \%, \phi=44^{\circ}$ \\
\hline
\end{tabular}

Table 2 Properties of Bima Geoteks ${ }^{\circledR}$ Woven Geotextile BW250

\begin{tabular}{ll}
\hline Weight & $250 \mathrm{gr} / \mathrm{m}^{2}$ \\
Thickness & $1.10 \mathrm{~mm}$ \\
Color & Black \\
Strip tensile strength & Warp $42.5 \mathrm{kN} / \mathrm{m}$, Weft $42.5 \mathrm{kN} / \mathrm{m}$ \\
Elongation at maximum load & $24 \%$ \\
Trapezoidal tear strength & $480 \mathrm{~N}$ \\
Water permeability at $100 \mathrm{~m}$ waterhead & $21 \mathrm{~L} / \mathrm{m}^{2} / \mathrm{sec}$ \\
Effective opening size (090) & $0.27 \mathrm{~mm}$ \\
UV light effect & UV stabilized \\
\hline
\end{tabular}

Experimental Setup A model test tank with the dimensions having length and width of $1 \mathrm{~m}$ each, and depth of $0.9 \mathrm{~m}$ was design and fabricated to perform the test. The whole tanks were made of steel, consisted of five panels; four side panels and one bottom panel. The horizontal and vertical sides of the model tank were stiffened by using steel angle sections at the top, bottom and middle of the tanks to avoid any lateral yielding during soil compaction in the tank and also while applying load at model pad foundation during the experiment. Sand was filled in the test tank in five layers to 
make sure the uniform compaction. In this research, the relative density of sand bed in the testing tank was maintained constant on the rate of $50 \%$ in such a way that sand was poured into the tank through a bucket assembly, which was moved by hand in consistent manner over the testing bed to achieve uniform sand distribution and sufficient compaction. The loading system composed of a load cell of one-ton capacity, which generates a downward displacement at a constant rate. This displacement was transformed into a force through a steel plank onto a-10 $\mathrm{cm} \times 10 \mathrm{~cm}$ pad foundation model made of $10 \mathrm{~mm}$ thick rigid steel plate, which placed at the center of a test tank filled with sand. A dial gauge of sufficient capacity was mounted onto the foundation model to measure the maximum load the foundation experienced before the failure took place. The geometrical configurations of the test tank model with the load and settlement measurement setup used in the experiment is shown in Figure 1.

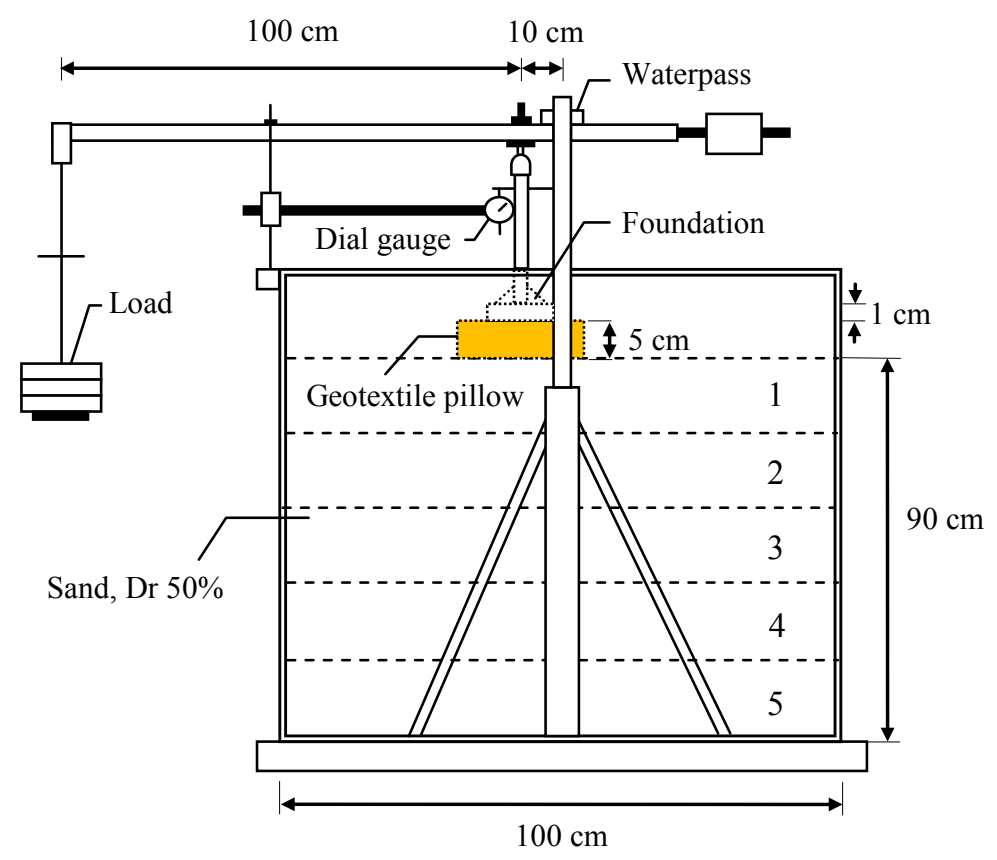

Fig. 1 Test tank model with load and settlement measurement setup

Test Procedure Pad foundation model was embedded first on sand at the centrifugally center of the testing tank. The tests were applied on three types of conditions: 1) using no geotextile, 2) using geotextile sheet, and 3) using geotextile pillow with dimensions of $40 \mathrm{~cm} \times 40 \mathrm{~cm} \times 5 \mathrm{~cm}$. For different experiments, either the geotextile sheet or the geotextile pillow was placed $1 \mathrm{~cm}$ below the foundation model. In the case of geotextile pillow, sand was put inside the pillow with different variety of relative densities, i.e. $30 \%, 50 \%$ and $70 \%$. Load application set up was simultaneously prepared and rested on the foundation model. After the testing box was prepared, all the measuring devices and connection were checked again to ensure the accuracy of data and safety. Estimated ultimate design load was assumed to be equal to or greater than ultimate load, as a result of the multiplication of ultimate bearing capacity calculated by the equations of Terzaghi (1943), Meyerhoff (1963) and Hansen (1970) and the unit area of foundation. The design load was divided by ten and applied in stages. The load was increased after the settlement on each loading stage stopped, which could be seen on the dial gauge. The counterweight on the opposite side was then balanced using the help of the waterpass. This loading procedure was kept repeated and at the same time, observations of the settlement were taken until the failure happened. At the end of each test, the load application was set up and foundation model were removed from the testing tank carefully. Based on the data recorded, log load versus log settlement relationship was then plotted and two intersecting straight lines were identified in the data points. Load was plotted on the horizontal scale 
and settlement was plotted on the vertical scale. The load corresponding to point of intersection gave the ultimate load and corresponding settlement was obtained. Furthermore, the bearing capacity was calculated by dividing the ultimate load by the plan area of the foundation. The same test procedure was performed for other experiments with different conditions.

The results of experimental measurement were compared among each other, as well as to the theoretical empirical calculations. Although the equations developed by Terzaghi, Meyerhoff and Hansen apply only on shallow foundation that does not take into account the presence of geotextile pillow as the reinforcement of the foundation soil, the comparisons were still conducted to demonstrate the reliability of any theory previously developed.

\section{Results and Discussion}

Based on the laboratory experiments, it was found that by placing the geotextile sheet in the experiment, it produced the value of ultimate load up to $120 \mathrm{~kg}$. Compared with the result of the same experiment without any reinforcement, the geotextile sheet added $50 \%$ increment of ultimate load of the pad foundation model. Due to the same size of the pad foundation model used in this research, the increase of ultimate load gave an impact to the increase of the bearing capacity with the same rate. Meanwhile, the use of the geotextile pillow with sand relative density inside the pillow of $30 \%, 50 \%$ and $70 \%$ gave ultimate loads of $200 \mathrm{~kg}, 400 \mathrm{~kg}$ and $500 \mathrm{~kg}$, respectively. It means the geotextile pillow produced $150 \%, 400 \%$ and $525 \%$ of increment of the bearing capacity, compared with the ones using no geotextile. Thus, it indicated that as the sand relative density inside the geotextile pillow increased, the ultimate load showed an increasing trend. Meaning, the bearing capacity of the same pad foundation model also went on increased. Figure 2 shows the relationship between log load and log settlement for pad foundation model with different type of conditions.

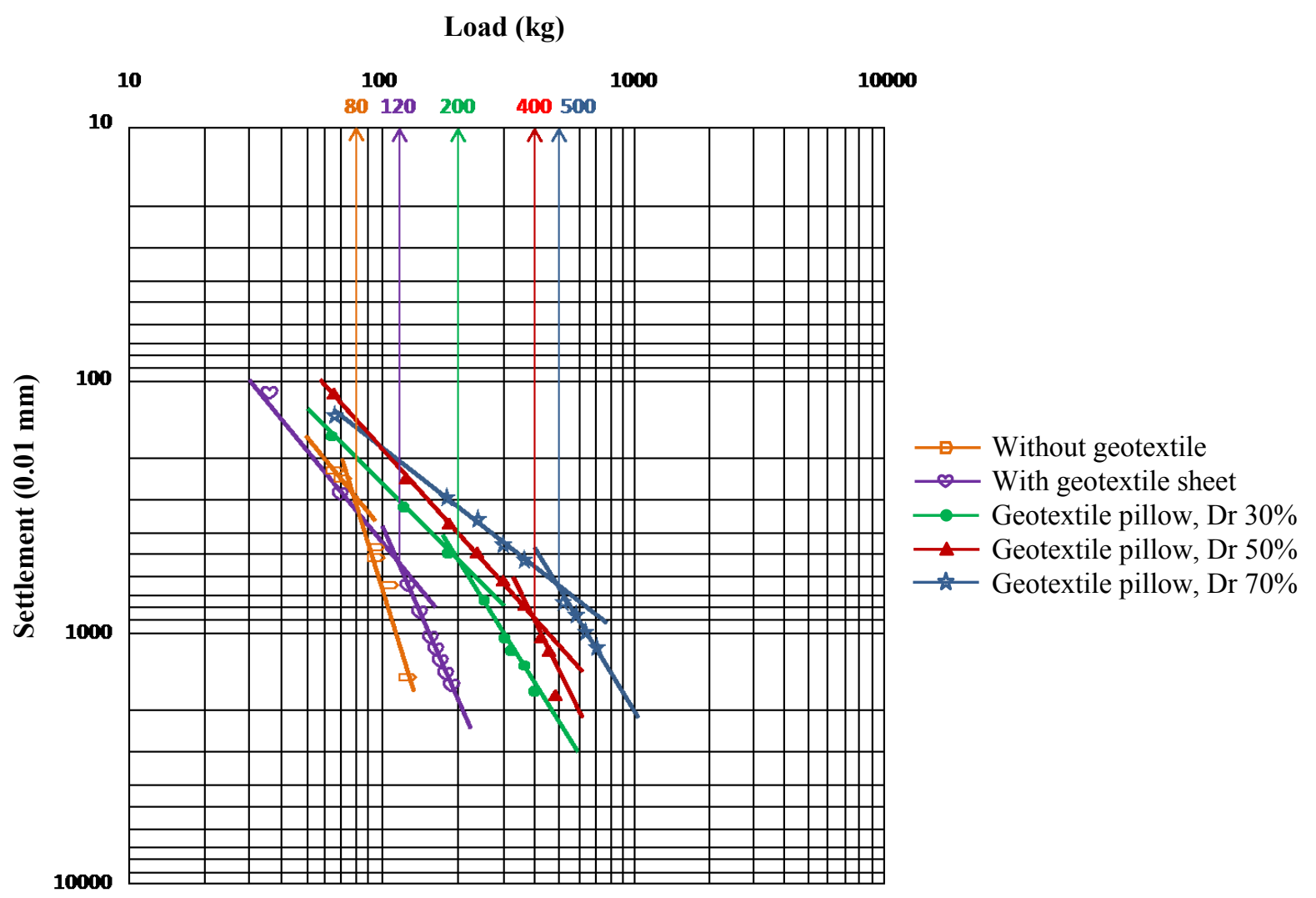

Fig. 2 Load and settlement relationship for pad foundation model with different types of conditions 
According to some references, due to some restrictions and assumption in all of classical formulations, most likely they do not always give reasonable results compared to the experimental results. It was proved in this research that the ultimate load obtained from the equations developed by Hansen, Terzaghi and Meyerhoff were lesser than the experiment result, i.e. $24.55 \mathrm{~kg}, 45.05 \mathrm{~kg}$ and $66.30 \mathrm{~kg}$, respectively. Anyhow, these values were still used in the comparison to determine the effectiveness of using geotextile, either installed as sheet or as pillow, for improving the ultimate bearing capacity of the pad foundation. The ratios between ultimate loads obtained from the laboratory experiements using geotextile pillow with variety of sand relative densities and the ones produced on different conditions, including the theoretical values are shown in Figure 3.

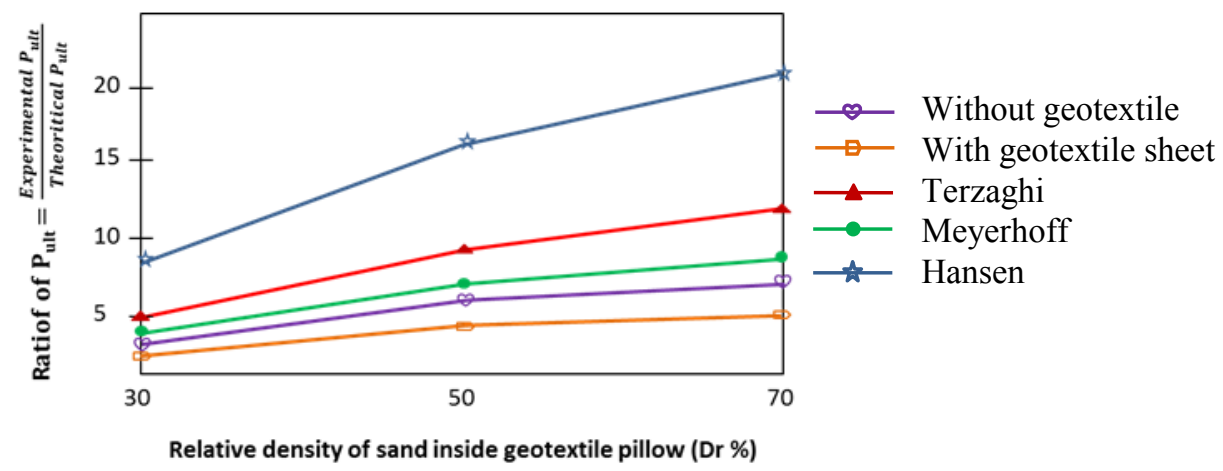

Fig. 3 Ratio of ultimate loads obtained by using geotextile pillow with different sand relative densities to the ones with different conditions and theoretical values

\section{Conclusion}

It can be concluded that the bearing capacity of pad foundation on sand has increased using geotextile materials, either in the form of sheets or pillow. The bearing capacity was proved to increase by $50 \%$ using a sheet of geotextile, compared to the one without any geotextile. Moreover, to the same condition, the use of a geotextile pillow with different sand relative densities inside the pillow, i.e. $30 \%, 50 \%$ and $70 \%$ improved the bearing capacity of the pad foundation model from $150 \%$ to $525 \%$. Among the experiment results using a geotextile pillow, the $66.67 \%$ addition of sand relative density increased the bearing capacity of a pad foundation by $100 \%$ and $150 \%$ with $133.33 \%$ of sand relative density. It showed that the increase of the sand relative density inside the geotextile pillow was directly proportional to the increase of the bearing capacity of the pad foundation.

\section{References}

[1] Bowles, E. Joseph: Foundation Analysis and Design, $5^{\text {th }}$ edition, McGraw Hill (2001)

[2] M. Braja Das: Principles of Foundation Engineering, $7^{\text {th }}$ edition, Cengage Learning (2011)

[3] Whitlow, Roy: Basic Soil Mechanics, Prentice Hall, $4^{\text {th }}$ edition (2001)

[4] Coduto, P. Donald: Foundation Design, Principles and Practices, $2^{\text {nd }}$ edition Prentice Hall (2000)

[5] Information on http://www.engr.utk.edu/mse/Textiles/Geotextiles.htm. 